\title{
A racionalidade da economia de comunhão e responsabilidade socioambiental: a gestão organizacional influenciada por valores espirituais
}

\section{The Rationality of Communion Economy and Socio-Environmental Responsibility: The Organizational Management Influenced by Spiritual Values}

\author{
Valdir FERNANDES* \\ Fernando Soares Pinto SANT'ANNA**
}

\begin{abstract}
RESUMO
Este artigo discute a inserção das dimensões social e ambiental nos processos de gestão por influência de valores espirituais. Esta discussão é feita a partir da análise crítica da experiência socioeconômica denominada Economia de Comunhão (EdC), destacando seus fundamentos valorativos em termos espirituais, éticos e morais como motivadores da inerência da dimensão socioambiental nestas organizações. Trata-se de uma experiência sui generis, nascida dentro dos limites de um movimento religioso, o Movimento dos Focolares. Atualmente conta com adesão de 735 empresas, principalmente de pequeno porte, localizadas em diversos países, que atuam nas mais variadas atividades, congregando finalidades solidárias com a atuação na economia de mercado formal. As reflexões aqui expostas evidenciam um tipo de gestão não apenas baseada nos critérios da racionalidade instrumental (eficácia, rendimento e desempenho), mas, também, fundamentadas na racionalidade substantiva (valores éticos, estéticos e morais).
\end{abstract}

Palavras-chave: gestão organizacional; economia de comunhão; responsabilidade socioambiental; racionalidade.

\begin{abstract}
This paper discusses the influence of spiritual values in the insertion of socio-environmental dimensions in management processes. A critical analysis of the socio-economic experience named Communion Economy is presented, which highlights the spiritual, ethical and moral values in this economy as inherent motivators of social and environmental considerations. It is a sui generis experience, born within the limits of a religious movement, the Movement of Focolares. It is currently active in 735 companies, mostly small ones, located in several countries, which operate in various economic activities and aggre-
\end{abstract}

\footnotetext{
" Cientista Social. Professor permanente do Mestrado Interdisciplinar em Organizações e Desenvolvimento da FAE - Centro Universitário Franciscano. Email: valdir.fernandes@live.fae.edu

${ }^{* *}$ Engenheiro Civil. Professor do Departamento de Engenharia Sanitária e Ambiental da Universidade Federal de Santa Catarina (UFSC). Email: santanna@ens.ufsc.br
} 
gate a dimension of solidarity to their formal market activity. The considerations presented here reveal a management form based not only on criteria of instrumental rationality (effectiveness, income and performance) but also on dimensions of substantive rationality (ethical, aesthetic and moral).

Key-words: organizational management; economy of communion; social-environmental responsibility; rationality.

\section{Introdução}

O pensador e economista inglês E. F. Schumacher constitui ainda atualmente importante fonte de inspiração para se pensar a gestão organizacional em bases éticas que enalteçam sentimentos, virtudes, valores qualitativos e espirituais. Schumacher (1983) foi hábil ao conciliar, ao menos no plano reflexivo, ética e economia, razão e fé. No mundo atual, existem diversos casos dessa tentativa de conciliar negócios e espiritualidade, cujos argumentos são que transparência, ética e compromisso socioambiental podem ser compatíveis com a razão da existência das empresas que é a produção de bens e serviços com a finalidade de geração de lucro.

Não obstante as dificuldades enfrentadas pelos empreendedores, tais como burocracia, custos financeiros e sociais, falta de crédito e informalidade, especulação financeira e um tipo de concorrência sem limites, nem sempre leal, cresce, por outro lado, o número de organizações buscando levar em conta as questões éticas e morais. Nesta perspectiva, o sucesso destas organizações não é necessariamente associado exclusivamente aos resultados financeiros, mas considera metas sociais e de responsabilidade ambiental.

Com uma visão diferenciada em relação ao economicismo, estas organizações ensejam um modelo de compatibilidade entre ética e economia. Embora mantenham as finalidades econômicas e de ganhos financeiros, não consideram estritamente estes fatores. Além da competência na gestão e da capacidade de aumento produtivo e dos lucros, ganham espaço no processo de tomada de decisão os fatores sociais e ambientais, associados não só a demandas de mercado, mas também a princípios éticos e morais. Como exemplo destas iniciativas em maior ou menor grau de comprometimento é possível citar "empresas éticas", de "Responsabilidade Social Empresarial", de "Economia Solidária" e de "Economia de Comunhão".

O objetivo deste artigo é analisar um destes exemplos de gestão organizacional influenciada por valores espirituais, absolutos, não tangíveis. Inserindo-se nos estudos de gestão ambiental em organizações, constitui uma tentativa de discutir como esses valores influenciam e qualificam os processos de tomada de decisão organizacional. O campo empírico escolhido para guiar esta discussão é o projeto socioeconômico Economia de Comunhão (EdC). A EdC, como passamos a nos referir à Economia de Comunhão, constitui uma iniciativa socioeconômica composta por empresas, na sua maioria de propriedade privada, cujos proprietários são membros do Movimento dos Focolares, um movimento religioso e social de caráter ecumênico e inter-religioso que surgiu no contexto da Segunda Guerra Mundial, em Trento na Itália, e se espalhou para todos os continentes. Atualmente conta com cerca de 5,5 milhões de membros, considerando todas as formas de participação, mais interna ou mais ao largo. Chegou ao Brasil em 1958 e tem, no país, cerca de 300 mil membros. Para maior aprofundamento sobre este movimento, sugere-se dentre outros, os trabalhos de Medeiros (2006) e Fernandes (2007, p. 88-110).

Tendo surgido no Brasil em 1991, a EdC se expande atualmente para muitos outros países em vários continentes. Trata-se de uma experiência sui generis, nascida dentro dos limites de um movimento religioso, o Movimento dos Focolares, que atualmente conta com adesão de 735 empresas, principalmente de pequeno porte, que atuam nas mais variadas atividades econômicas congregando finalidades solidárias com a atuação na economia de mercado formal. Ou seja, não diferem em termos de estrutura de meios de produção de outras empresas capitalistas, mesmo se têm como um dos seus princípios a distribuição beneficente de parte dos lucros. A característica que interessa a esta análise, entretanto, é o arcabouço valorativo a partir do qual estas empresas são geridas e administradas e que estabelece uma distinção em termos de critérios racionais de tomada de decisão.

As reflexões aqui construídas têm por objetivo qualificar, a partir de modelo de análise composto pelas categorias racionalidade instrumental e substantiva, a inserção da dimensão socioambiental nas empresas de EdC. A exploração das nuances da EdC neste estudo é feita a partir 
do pressuposto de que a dimensão socioambiental consiste na relação de interdependência entre sociedade e natureza, numa perspectiva dialógica e sistêmica.

A coleta de dados foi realizada por meio de entrevistas semiestruturadas, na forma de colóquios, tanto com empresários como com outros membros envolvidos no projeto EdC e também com membros do Movimento dos Focolares ligados à EdC; questionários abertos enviados às 121 empresas brasileiras de EdC e observação direta em 7 empresas coligadas a este projeto.

\section{Razão capaz de comunhão - Luigino Bruni}

Para Bruni (2005, p. 85), a racionalidade de comunhão é uma racionalidade de cooperação e de compreensão da interdependência recíproca, "substancialmente diferente da cooperação típica da economia dos mercados". Numa racionalidade de mercado, o "racional" é muitas vezes não cooperar, porque pela lógica de mercado a não cooperação é mais vantajosa individualmente, mesmo que coletivamente essa atitude possa representar prejuízo. Para demonstrar isto, Bruni (2005) se utiliza da teoria dos jogos ${ }^{1}$, aplicada a uma situação de coleta seletiva de lixo onde os dois agentes têm a opção de cooperar ou não.

Seguindo o exemplo de Bruni (2005) e utilizando-se de situações ideais ${ }^{2}$, no que se refere aos critérios instrumentais, econômicos e coletivos, constrói-se a seguir um exercício relativo às vantagens ou não da cooperação no que se refere a tratar ou não os efluentes lançados num rio. Ressalta-se que não se trata da construção de um axioma, mas apenas de um exercício lógico-dedutivo entre duas empresas fictícias. Assim, considerando duas empresas que agem apenas pela racionalidade instrumental com fins econômicos e levando em conta apenas a questão da competitividade e do interesse individual em termos de custo de produção, a equação poderia ser descrita da seguinte forma: se a primeira empresa fizer o tratamento, apostando que a outra também o fará, não terá vantagem alguma, assim como não terá a outra empresa, pois ambas continuariam em absoluta igualdade de condições em termos de competitividade. Se, ao invés, a primeira empresa não fizer o tratamento, apostando que a outra o fará, terá grande vantagem competitiva, já que não terá que incorporar nos seus produtos os custos do tratamento, enquanto a outra empresa terá este custo. Por fim, se a primeira empresa não fizer o tratamento apostando que a outra empresa também não o fará, manterá a igualdade de condições de competir.

A lição que se tira deste exercício é que, considerando apenas os aspectos de competitividade, levando em conta apenas os custos, tratar o efluente não representa vantagem alguma em nenhuma das situações, pois o máximo que se consegue é ficar em igualdade de condições, se ambas decidirem tratar ou não tratar o efluente. Por outro lado, significa um risco, pois, se uma empresa decidir tratar o efluente e a outra não o fizer, a primeira ficará em desvantagem competitiva, devido ao custo de tratamento que terá que incorporar, enquanto a segunda empresa não terá este custo. Portanto, o melhor cenário para qualquer uma das empresas é não tratar o efluente e apostar que a outra o fará, podendo, na pior das hipóteses, ficar em pé de igualdade competitiva se a outra também não fizer o tratamento.

Evidentemente que nessa simulação não está contemplado o contexto coletivo, social e comunitário da empresa. Parte-se de uma situação ideal onde o único critério é a instrumentalidade, cuja finalidade é a vantagem competitiva e, consequentemente, econômica. Analisando a mesma situação pelo enfoque coletivo e da cooperação preconizado por Bruni (2005), quando propõe uma racionalidade de comunhão na qual são considerados os aspectos éticos, estéticos e morais da poluição do rio, também em termos de tipos ideais, teríamos uma situação completamente inversa: se a primeira empresa decidir tratar os seus efluentes e a segunda empresa não o fizer, terá investido a sua parte e contribuído com $50 \%$ para não poluir o rio, proporcionado um ganho de $50 \%$ a ambas e à comunidade. Terá, portanto, o retorno do seu investimento na proporção que investiu, enquanto a outra empresa igualmente obterá ganhos sem, no

\footnotetext{
${ }^{1}$ A teoria dos jogos é um modelo abstrato e dedutivo que não descreve como as pessoas de fato tomam decisões, mas sim como procederiam ao tomarem decisões em situações competitivas se elas fossem inteiramente racionais. A base da teoria dos jogos são as decisões racionais tomadas de forma a antever o próximo movimento do concorrente (jogador) e a interdependência. O resultado depende do que os dois fizerem. Cada um tem que tentar prever como o outro se comportará. A teoria dos jogos é, sobretudo, aplicável nas relações internacionais em situações estratégicas (DYE, 1994).

${ }^{2}$ Situações ideais, tal como entendemos nesse caso, é um modelo teórico construído a partir de fenômenos isolados da ligação entre eles sem que o tenhamos testado empiricamente (como prevê o modelo criado por Weber). Não se trata, portanto, de uma hipótese de algo encontrável na realidade, mas apenas de um recurso metodológico para descrever e explicar a realidade. Também não é um tipo ideal desejável no sentido normativo ou de ser uma referência, um modelo especial, mas apenas um tipo no sentido lógico que reúne características distintivas de um determinado agente ou grupo.
} 
entanto, investir, mas terá em contrapartida uma dívida com a outra empresa e com a comunidade. Se a primeira tratar os seus efluentes e a segunda igualmente o fizer, ambas terão investido $50 \%$ para não poluir o rio e proporcionado um ganho de $100 \%$ a todos. Desta forma, as duas empresas terão o retorno dos seus investimentos na proporção de 2 para 1 , ou seja, em dobro, e ainda estarão sem qualquer dívida com a comunidade. Na terceira possibilidade, se decidirem pelo não tratamento dos seus efluentes, não terão feito qualquer investimento, mas também não terão qualquer retorno e ainda ficarão com uma dívida com a comunidade e uma com a outra dos $50 \%$ que era de sua obrigação.

A primeira situação é a explicação simplificada das motivações e da lógica pela qual a conservação do meio ambiente sempre ficou fora do processo de desenvolvimento e do modelo produtivo capitalista, considerando uma situação ideal de competição, na qual predominam os critérios da racionalidade instrumental e as finalidades econômicas (eficácia, rendimento e desempenho).

Não se ignora, porém, que numa situação real outros critérios de racionalidade possam estar presentes (e estão), tais como valores pessoais dos empresários e da própria cultura da sociedade da qual faça parte (éticos, morais, estéticos, políticos, ideológicos...), o poder coercitivo e incentivador do Estado, e a própria pressão da sociedade civil e dos stakeholders ${ }^{3}$. Da mesma forma, não se pode negar que a cooperação é possível em termos instrumentais, baseada no princípio da troca. Isto é, que a cooperação seja condicional, como explica Bruni (2005). Eu trato o efluente da minha empresa se você tratar o efluente da sua empresa. Além disso, a cooperação em termos instrumentais pode surgir de uma necessidade imposta pela realidade. Ambos temos que usar a água do rio, portanto, isso só é possível se não jogarmos o efluente poluído no rio. Basta que um não coopere, poluindo o rio, para que o outro também não possa usar a sua água. O problema é que nessas situações a cooperação durará sempre até que a condicionalidade seja rompida ou até que a necessidade de água deixe de existir para um dos agentes.

Na segunda variável desta equação, está-se considerando também uma situação ideal, na qual há o predomínio dos valores coletivos como elementos fundamentais de uma racionalidade substantiva ou de comunhão. Da mesma forma, como na situação acima, é sabido que numa situação real, mesmo onde haja o predomínio de uma racionalidade de comunhão, estão presentes também outros critérios de racionalidade, como os da racionalidade instrumental (eficácia, rendimento e desempenho). Entretanto, o resultado do exercício, numa situação na qual houvesse predomínio dos critérios substantivos, poderia ser explicado pelo que Bruni (2002) define como a não condicionalidade da reciprocidade ou a gratuidade, que é um dos elementos fundamentais de uma racionalidade de comunhão.

Segundo Bruni (2002), a reciprocidade é geralmente entendida em economia como um elemento de condicionalidade. Realiza-se uma ação ou coopera-se, com a condição de que o outro também o faça. A questão que está posta é: será possível uma racionalidade na qual esteja presente a reciprocidade não condicional? Segundo Bruni, em Hume (2000) está expressa a seguinte equação: ajudo você, com a condição de que você me ajude. No modelo da we rationality de Hollis (1998) e Sugden, (1993) esta equação aparece como: "ajudo você porque é meu amigo", na qual a expressão "amigo" já indica outro fato precedente. Sendo amigos, consequentemente se é parte do mesmo grupo, da mesma comunidade, o que já pressupõe certa reciprocidade e condicionalidade. Entretanto, numa racionalidade de comunhão, Bruni (2002) argumenta que há um elemento que transcende a reciprocidade no seu aspecto condicional. Trata-se da gratuidade em que a retribuição não é condição prévia nem necessária de um comportamento, mas apenas desejável. Portanto, não é que não se espere a reciprocidade, porém esta deve ser algo livre numa dimensão do tempo, não condicionada: "Numa perspectiva estática não se capta a dinâmica da reciprocidade ou, como prefiro dizer, da $\mathrm{Co}$ munhão. Se, de fato, num comportamento animado por uma racionalidade de comunhão não há uma condicionalidade a priori, existe, porém, certa condicionalidade a posteriori" (BRUNI, 2002, p. 63, grifos originais). Ou seja, não há antes da ação a pretensão de que ela seja correspondida, mas há uma consequência da ação que pode resultar num ato recíproco. A ação é gratuita e desencadeia uma reação também gratuita que se torna um ato recíproco. Em outras palavras, a reciprocidade não está em quem doa, mas em quem recebe. O princípio da reciprocidade não é o de doar algo com a condição de receber outra coisa em troca. Esse é um princípio de troca. O princípio da reciprocidade é a gratuidade, a partir de um valor intrínseco motivador que porta na sua natureza a liberdade de que um ato gratuito torne-se recíproco.

${ }^{3}$ Stakeholders são todos os indivíduos ou grupos que exercem ou sofrem influência sobre e pela organização. 
Nesse sentido, voltando ao exercício acima, o tratamento de efluente na empresa não é feito com a condição de que outras empresas também o façam, mas porque existe convicção de que se pode e se deve fazer a própria parte, motivado por uma obrigação ética ou moral, a partir da qual a conservação do meio ambiente é um valor intrínseco. Segundo Bruni, essa seria uma atitude diversa daquela baseada na racionalidade econômica, porque "respeita o ambiente, paga os impostos ou constrói a sua casa respeitando as diretrizes do plano diretor [...], porque para a pessoa, esses comportamentos são valores, porque the dão uma recompensa intrínseca e não só instrumental" (BRUNI, 2005, p. 93, grifo original). Ainda para este autor, essas são questões de cooperação, que terão plena eficácia se também os outros agentes envolvidos se comportarem do mesmo modo sem, no entanto, tornar esse comportamento condicionado em termos de reciprocidade. A reciprocidade somente adquire valor se for suscitada por uma atitude de gratuidade. Numa racionalidade de comunhão, a cooperação individual não depende da cooperação de outros indivíduos e nem da reciprocidade, porém torna-se uma atitude coletiva e recíproca, quando muitos indivíduos agem de maneira análoga, com base na mesma racionalidade. Como consequência, a eficácia da ação individual, gratuita, tende a ser maximizada, porque se torna ação coletiva.

O valor que é componente intrínseco da ação refere-se aos valores e à virtude que em si já é um valor intrínseco. "A virtude é praticada por ter um valor intrínseco, não devido à conta custo/beneficio". [Ou seja, a racionalidade de comunhão não é] "um encontro de interesses", mas "um encontro de gratuidades" (BRUNI, 2005, p. 95 e 130). É essa característica, segundo Bruni, que torna as empresas de EdC diferentes de uma associação ou clube, porque torna as suas relações "abertas" e "transitivas", "gratuitas" e "não condicionais".

Além da não condicionalidade da reciprocidade ou a gratuidade, uma racionalidade capaz de comunhão, segundo Bruni (2002), é composta ainda por outras três dimensões complementares e inseparáveis: o universalismo, a relacionalidade e a racionalidade expressiva.

Universalismo: é o primeiro ponto de uma racionalidade de comunhão, uma vez que a referência é a humanidade inteira e não um grupo específico ou o indivíduo, mas o universo. $\mathrm{Na}$ EdC essa característica se concretiza, por exemplo, com a doação de uma parte dos lucros para formar uma cultura de partilha; no caso da preocupação com a conservação ambiental, ou seja, da inserção da dimensão ambiental nas empresas, o elemento universalismo remete a uma referência que não é somente a competitividade da empresa e a sua sobrevivência no mercado, mas a preocupação é com a Terra como um todo e com a humanidade.

Relacionalidade: "A pessoa é sempre vista numa relação construída com o outro", não porque haja um interesse ou porque se é altruísta, "mas porque toda a decisão nasce, de fato, sempre de uma relação com outra pessoa, dentro de uma relação". O próprio ser humano só existe a partir da relação com outros seres, o que exige uma compreensão diferente do comportamento racional (BRUNI, 2002 , p. 59). O respeito ao meio ambiente e a preocupação com sua conservação, nesta perspectiva, estão ligados ao axioma da espiritualidade da unidade em que tudo está em relação amorosa com tudo:

$\mathrm{Na}$ terra tudo está em relação de amor com tudo [...]. $\mathrm{O}$ amor é também a lei do relacionar-se entre os seres humanos, do viver e do conviver [...]. O amor é a substância da qual as coisas foram criadas e por isso estão em comunhão de amor entre si, em relação de amor. Por isso, se o riacho deságua no lago é por amor. Se um pinheiro se ergue junto a outro é por amor... (LUBICH, 1992).

Racionalidade expressiva: A racionalidade expressiva indica o desejo de exprimir algo relativo à relação estabelecida ou a ser estabelecida. "Uma racionalidade capaz de comunhão deve ultrapassar a simples lógica instrumental [...]. Levo uma garrafa de vinho quando sou convidado a um jantar não para obter instrumentalmente algum objetivo pessoal, mas para exprimir que o convite agradou" (BRUNI, 2002, p. 60). Da mesma forma, quando se produz ou se adquire um produto ecologicamente correto não se faz para otimizar uma relação meios e fins, mas para exprimir um valor, uma opção ética. Assim ocorre também com quem adere à EdC, segundo Bruni (2002). Não o faz por causa de cálculos e resultados baseados em meios e fins, mas pela crença num estilo de vida e de economia. Da mesma forma, na simulação da teoria dos jogos, uma empresa trataria os efluentes ao invés de lançá-los ao rio, faria isso motivada por preocupações coletivas que transcendem as vantagens econômicas individuais, baseadas na racionalidade instrumental, numa equação meios/fins. Agiria assim, motivada por valores intrínsecos (éticos, morais, estéticos) e a sua atitude é expressão destes valores e da noção de coletivo.

Evidentemente que seria ingênuo acreditar que possa haver uma relação destituída de interesses materiais ou de 
outra ordem. O próprio berço no qual se desenvolveu a EdC e a proposição de uma racionalidade capaz de comunhão, nos moldes como propõe Bruni, é o bojo de um movimento social cristão. Apesar da mensagem de unidade do Movimento dos Focolares (MEDEIROS, 2006), por trás de uma ideologia há sempre um interesse que, embora muitas vezes não sendo material, via de regra preserva a natureza de conquista e de expansão típicas das ideologias.

Assim, cabe ressaltar que, ao contrapor a relação instrumental direta da teoria dos jogos à substantividade da racionalidade de comunhão e do princípio da reciprocidade, está-se contrapondo dois modelos abstratos cujos limites são a própria prática. A EdC preserva a estrutura de meios de produção capitalistas, assim como opera segundo os critérios da racionalidade instrumental. Ao mesmo tempo, inova ao aplicar princípios de redistribuição dos lucros. A questão é: em que grau isto ocorre a ponto de defini-la como uma prática substantiva e de reciprocidade de gestão, por um lado, e para além dos limites de um movimento religioso, por outro? Até que ponto a racionalidade de comunhão preconizada por Bruni (2002; 2005), a partir de sua leitura da prática da EdC, é possível no contexto da economia formal de mercado enquanto princípios de gestão, que supera a ascese religiosa? Estas questões perpassam a discussão principal deste artigo, que é: até que ponto é possível inferir que esta racionalidade de comunhão, por ser mais substantiva enquanto modelo abstrato, contempla em termos práticos as questões ambientais e sociais, como querem afirmar muitos de seus adeptos e analistas?

\section{Economia de comunhão: a influência dos valores espirituais na gestão organizacional e na responsabilidade socioambiental das empresas vinculadas}

Buscando compreender o "lugar" da dimensão ambiental no projeto $\mathrm{EdC}$ e, consequentemente, na gestão das empresas, os resultados obtidos dão conta de que $70 \%$ dos empresários pesquisados consideram que a responsabilidade socioambiental é parte inerente do projeto EdC já na sua concepção. Os outros $30 \%$ também consideram esta inerên- cia, mas afirmam que este compromisso não é amplamente divulgado para todos os empresários que aderem ao projeto ${ }^{4}$.

Quanto à formalização deste compromisso nas estratégias das suas empresas, as respostas sugerem que estes compromissos estão presentes na Visão, na Missão ou em programas de planejamento e gestão da maioria das empresas. A maioria dos empresários que respondeu ao questionário afirma que este compromisso é amplamente divulgado para todos os interessados nos ambientes interno e externo de suas respectivas empresas. $40 \%$ dos empresários afirmaram manter algum programa ou ações de sensibilização e educação sobre a dimensão socioambiental em suas empresas. As respostas às entrevistas semiestruturadas na forma de colóquios revelaram que estes compromissos estão formalmente inseridos nos princípios da $\mathrm{EdC}$ enquanto estilo de gestão e de produção, como passamos a apresentar a seguir. Nestas entrevistas, a justificativa recorrente é que o amor à natureza e ao próximo são aspectos inerentes da espiritualidade da unidade ${ }^{5}$ e, portanto, também devem ser contemplados na prática das empresas de EdC. O entendimento comum é que não é possível ser empresa de EdC se a responsabilidade socioambiental não for considerada também como um valor, como exemplifica o discurso a seguir:

Tanto a responsabilidade social como a cultura ambiental estão embutidas no "DNA" da EdC. As empresas de EdC direcionam suas ações à conservação da natureza, à formação dos funcionários, ao respeito pelos clientes e fornecedores e ao bem estar global.

Os discursos induzem para a existência de um compromisso moral e ético, próprio da espiritualidade do Movimento dos Focolares, ou seja, a conservação da natureza, ao lado de outras dimensões de responsabilidade social, é condição para se dizer "empresa de EdC". Essa postura sugere em termos teóricos que, independente de pressões externas, o empresário de EdC deve considerar as dimensões sociais e ambientais na gestão empresarial. Segundo os próprios empresários, a preocupação com a conservação ambiental e com os problemas sociais devem ser parte de uma mudança mais substancial proposta pela EdC enquanto projeto de sociedade e "que deve se tornar

\footnotetext{
${ }^{4}$ No que se refere à amostra da pesquisa, o questionário foi enviado a 121 empresas, que era na época da pesquisa (2006 e 2007) o número total de empresas de EdC no Brasil. Dessas, cerca de $40 \%$ responderam ao questionário, o que constituiu a amostra dos questionários abertos enviados às empresas.

${ }^{5}$ Espiritualidade segundo a qual é regido o Movimento dos Focolares e a própria EdC.
} 
um processo natural de educação" a partir de um modelo próprio de gestão.

A dimensão socioambiental na $\mathrm{EdC}$ aparece, em termos de discurso, como uma dimensão substancial inerente à própria proposta na sua concepção e nos seus princípios ao lado de outros aspectos inerentes como os comerciais e de gestão das empresas. Essa substancialidade é proporcionada diretamente pela religiosidade e pela ética cristã impressa no projeto da EdC e consequentemente na gestão empresarial. O principal valor citado por praticamente todos os entrevistados é "amor ao próximo", conforme ilustra o discurso:

Não é possível afirmar que se ama o irmão se não se ama a natureza. A proposta da EdC é amar a todos. Amar o funcionário, o cliente, o concorrente, o Estado. E amar a todos é também amar o meio ambiente. Dentro do meu conceito de $\mathrm{EdC}$, o meio ambiente faz parte e está inserido no contexto principal da linha de ação da EdC, assim como amar o concorrente; amar o funcionário; amar o governo; amar o inimigo. Por isso, vejo que a proposta da Economia de Comunhão é "Amar a Todos" e, como consequência, o meio ambiente também.

O "amar a todos" é o eixo central identificado em todas as entrevistas e, segundo os empresários, é o que deve guiar a EdC. Este "distintivo", como os próprios empresários e demais membros do Movimento dos Focolares definem, está muito presente em suas falas. Qualquer que seja o empresário vinculado à EdC, se indagado sobre o que deve guiar a EdC e as empresas, a resposta expressa quase sempre o mesmo conteúdo:

Nós acreditamos que a EdC não é um projeto nosso, mas de Deus, e os projetos de Deus são sempre Amor. Por isso uma empresa de EdC deve ser Amor para com os outros [...]. Ela é Amor quando suas ações são em prol do bem comum, não só para os seus interesses ou grupos de interesses, mas para todos.

O amor cristão, segundo os empresários, é que os motiva a serem solidários, doando inclusive parte dos seus lucros para finalidades de ajuda financeira aos "pobres" cadastrados pelo Movimento dos Focolares. Motiva-os também a contribuir com a "coletividade", por meio de práticas tais como pagar em dia e integralmente os impostos (uma das exigências do projeto $\mathrm{EdC}$ ), ainda que tenham a consciência de que muitas vezes são valores mal utilizados pelos administradores públicos:

Chiara Lubich nos ensina que ao homem nu pertence o manto que mantemos no armário. Ao faminto, o pão que estocamos. Ao pobre, o dinheiro que acumulamos. Ser empresário da EdC é ser solidário, viver sempre com espírito de comunidade, fazendo da empresa lugar de comunhão. Antes de ser empresários temos que ser irmãos de todos [...].

Um dos empresários entrevistados afirma que, ao aderir à EdC, logo percebeu que não se tratava apenas de doar parte de seus lucros, era preciso ir além:

Repartir os lucros é apenas um dos passos a serem dados de uma longa caminhada para construir uma nova forma de fazer economia [...]. Essa nova economia fundamenta-se, em síntese, em colocar em prática a arte de "amar a todos" que, por sua vez, contempla todos os outros aspectos, entre os quais o respeito, o amor à natureza. Aderir à EdC é rever e submeter todas as ações e estratégias individuais e da empresa a esse princípio que é simples, mas ao mesmo tempo grandioso.

Visualizam-se, assim, as motivações dos empresários que aderem à EdC e também um modelo de ação, segundo os princípios norteadores da EdC. Esses princípios têm como ambição nortear ou favorecer, como afirmam os empresários, uma concepção de um agir econômico que transcenda o objetivo puramente econômico e vise abranger outros aspectos da vida em sociedade, tais como a dignificação do trabalho, a qualidade de vida, a ética, o respeito à natureza, fundamentando-se principalmente na solidariedade:

A Economia de Comunhão trabalha para estimular a passagem da economia e de toda a sociedade, da cultura do ter para a cultura da partilha. Uma das palavras chaves da EdC é "felicidade". E a felicidade está na harmonia, no equilíbrio. É um modelo de gestão baseado nos 7 aspectos. A preocupação com a interdependência. A relação de amor contida na relação entre os aspectos. A providência. 
Nas visitas às empresas de $\mathrm{EdC}$, observou-se que a dimensão socioambiental é considerada, embora haja casos em que o discurso é bem mais avançado que a prática. Há exemplos de empresas com Sistema de Gestão da Qualidade e Ambiental, certificado conforme as normas ISO 9001 e 14001. Uma das empresas recebeu prêmio de destaque ambiental fornecido pelo Conselho Municipal de Defesa do Meio Ambiente - CODEMA - do município-sede. Esses dados confirmam em parte as respostas ao questionário, assim como os discursos dos empresários tanto nos Congressos de EdC como nas respectivas empresas. Corroboram, também, a tese de Bruni $(2002 ; 2005)$. Nesse sentido, um dos empresários relata que, na sua empresa, o meio ambiente é visto como parte integrante de todo o processo produtivo e, por isso, tudo é feito considerando-o também como uma dimensão da produção.

Em nossa empresa aproveitamos o máximo de luz solar para reduzir o consumo de energia elétrica, só imprimimos documentos que precisam ser de fato impressos, usamos as duas faces dos papéis de escritório e assim por diante. Nosso lixo orgânico é direcionado para coleta pública, os papéis são direcionados à reciclagem, sendo doados a um casal de idosos que ganham seu sustento coletando papéis e papelões, e o lixo industrial é coletado por empresa especializada, tendo seu destino de acordo com a legislação local.

Há casos em que o reaproveitamento dos resíduos é quase total, como numa empresa de rotomoldagem de materiais plásticos - produtos para construção civil e saneamento ambiental, tais como fossas e caixas de água:

Aqui os resíduos são reaproveitados na sua quase totalidade. $\mathrm{O}$ fato de ser termoplástico possibilita o seu reaproveitamento. Pouca coisa é descartada, como resíduos orgânicos e resíduos de manutenção, que são em pouca quantidade. Papel, plástico e alumínio são reciclados. Para o tratamento dos resíduos orgânicos estamos desenvolvendo um processo de compostagem.

O mesmo ocorre em outra empresa que produz embalagens, na qual há um processo de reaproveitamento de todo o material que seria descartado, assim como da água utilizada no processo:

Todo o material usado é reaproveitado, ou seja, mesmo que saiam frascos com defeitos, eles são moídos e misturados com material granulado e extrusados novamente. A água que utilizamos para refrigeração dos moldes circula em circuito fechado, sem poluentes.

Em outra empresa ${ }^{6}$ (fundição), cujo resíduo principal é areia de fundição, aproximadamente $60 \%$ da areia consumida é recuperada, sendo reaproveitada no processo. A parte descartada é utilizada na produção de artefatos de cimento: blocos, pisos, tijolos.

Nosso principal resíduo é a areia de fundição. Aproximadamente $60 \%$ da areia consumida é recuperada e reaproveitada no processo. A parte descartada é utilizada na produção de artefatos de cimento: blocos, pisos.

$\mathrm{O}$ aspecto inovador da $\mathrm{EdC}$, entretanto, não são as ações individuais das empresas em prol da conservação ambiental, mas o elemento motivador. Se, por um lado, as dimensões sociais e ambientais não são consideradas como critério de tomada de decisão, por outro lado o elemento motivador, que é a ascese religiosa, as torna inerentes. Esse elemento, que pôde ser visualizado empiricamente em algumas empresas de EdC, tem forte presença no discurso que retrata o compromisso dos empresários com os princípios da EdC:

Em minha opinião o meio ambiente ou desenvolvimento sustentável é parte integrante dos princípios e práticas da EdC. Entendo (esta é também minha experiência) que, quando o empresário adere à EdC, mais que dedicar-se a esta causa passa a assumir um novo comportamento que, traduzindo em poucas palavras, o torna sensível e comprometido com as causas ligadas ao Desenvolvimento Sustentável.

Segundo os empresários, a fidelidade a esses compromissos não tem como recompensa ganhos econômicos, em-

\footnotetext{
${ }^{6}$ Embora não tenha sido possível uma visita a esta empresa, os dados secundários coletados demonstram que ela é um caso emblemático no qual a dimensão ambiental é tida como intrínseca.
} 
bora não se negue que eles existam, mas está fundamentado na gratuidade - que é um elemento da própria religiosidade e da fé. Ou seja, a base fundamental não é material, mas substancial. São os valores assumidos individual e coletivamente que explicam as ações das empresas de EdC em prol da conservação ambiental e a distribuição beneficente de lucros. Portanto, não são empresários "ambientalistas" ou filantropos; tampouco agem motivados apenas por pressões do Estado ou do mercado. O que é evidenciado pelos discursos é um compromisso com o arcabouço valorativo proposto pela EdC enquanto concepção. Nesse sentido, pode-se afirmar que é a intensidade da aplicação do princípio "amar a todos", no sentido cristão, que define o maior ou menor grau das ações em termos de responsabilidade socioambiental das empresas de EdC.

No rol das empresas de EdC no Brasil, entretanto, existem também exemplos de empresas que ainda não aplicam os princípios socioambientais segundo rezam os princípios da EdC. Observou-se, em pelo menos um dos casos, que sobram inadequações ambientais e as condições de trabalho estão abaixo do tolerável (insalubridade devido ao excesso de calor; excesso de ruído; falta de circulação de ar; má disposição da cadeia de produção; falta de equipamentos adequados ao calor e ao ruído; falta de equipamentos de segurança). Mesmo assim, o cuidado com os funcionários e com o meio ambiente está muito presente no discurso dos empresários, que afirmam ser essa uma das suas preocupações mais importantes. O problema, segundo os empresários desta indústria, é que a incorporação da conservação ambiental de forma plena em todas as etapas do processo produtivo é impossível na atual circunstância. Primeiro, porque uma completa readequação nesse momento seria economicamente inviável, dado o estágio em que a empresa se encontra. Segundo, os empresários em geral se ressentem da falta de programas de apoio técnico e financeiro por parte do Estado. Nesse sentido, a situação de certas empresas de EdC não é diferente de outras pequenas empresas brasileiras que buscam a adequação ambiental e a manutenção da competitividade. Esse fato revela que existem também empresas de EdC em diversos níveis de aplicação dos seus princípios.

Não obstante o grande entusiasmo dos entrevistados ao falar da EdC e de suas empresas, em alguns casos o observador atento percebe que há uma disparidade entre o que se diz e o que elas realmente são em termos socioambientais. A explicação para esta contradição em termos de proporção entre o discurso e a prática e entre o projeto EdC e a sua concretização no dia a dia das empresas, segundo os empresários questionados, é que as empresas, embora se comprometam a se adequar segundo os princípios de $\mathrm{EdC}$, precisam de certo tempo para isso. Precisam continuar produzindo e, ao mesmo tempo, têm que ir consertando as inadequações. Ou seja, há um longo caminho a ser percorrido no sentido de materializar o projeto. Um bom exemplo desse fato é a empresa onde a dimensão ambiental ainda não foi incorporada, mas o comprometimento da comunidade trabalhadora com a filosofia da EdC é mais evidente do que nas demais.

Enquanto em outras empresas a EdC é um movimento mais de empresários do que de organizações, conforme constatou Gonçalves (2005), nesta empresa esse movimento congrega também a comunidade trabalhadora. Ali é realizado um projeto de valorização pessoal e humana dos empregados como parte integrante do projeto EdC. Esse projeto abrange os funcionários e suas esposas (os empregados são todos homens, com exceção do setor administrativo). A empresa estimula os funcionários, que na maioria têm apenas o ensino básico, a completar os estudos, oferecendo, em convênio com o município e com o Estado, os cursos de ensino fundamental e médio dentro da própria empresa. Além disso, como forma de integração, os empresários mantêm atividades lúdicas fora do expediente, das quais participam juntamente com os empregados como forma de fortalecimento do aspecto relacional. Essas atividades lhes proporcionam uma maior aproximação dos empregados e a construção de relacionamentos que extrapolam o limite profissional (patrão/empregado) e estabelecem maior confiança recíproca, afirmam os empresários. É essa confiança recíproca que permite envolver os empregados no projeto EdC e obter assim o comprometimento não só profissional, mas também ideológico. Além disso, a empresa mantém um convênio com uma entidade de recuperação de dependentes químicos para recolocação profissional, assumindo o compromisso não só de oferecer emprego, mas de acompanhamento do processo de recuperação. As atividades com as esposas dos funcionários são atividades lúdicas, de artesanato e de integração e socialização, nas quais participam principalmente as mulheres desempregadas. A atividade de artesanato tem gerado inclusive incremento em termos de renda familiar e é desenvolvida num espaço integrado à empresa, onde funciona também a escola.

Estes exemplos demonstram que não há ainda uma padronização em termos de gestão nas empresas de EdC. Embora regidas por princípios únicos que contemplam 
tanto a dimensão ambiental como a dimensão social, cada empresa constrói o seu modelo de gestão. Esse fato, porém, provoca um descompasso entre as empresas. Em algumas a dimensão ambiental é priorizada, enquanto em outras essa priorização é da dimensão social. De um modo geral, observou-se que em termos práticos a inserção da dimensão ambiental ainda é tímida se comparada com a aplicação dos outros princípios de EdC. Por outro lado, é inegável que a sua presença no discurso dos empresários denota uma constante preocupação. As inadequações ambientais e das condições de trabalho "incomodam muito", afirma um dos empresários, mas é preciso tempo para corrigi-las. Do contrário, corre-se o risco de "quebrar". Este empresário, a exemplo de outros, afirma tratar-se de uma experiência em curso que, embora baseada em princípios revolucionários, "ainda tem muito chão pela frente" para concretizar suas proposições.

O fato novo observado nas empresas de EdC, portanto, é uma postura declarada no sentido de melhorar tanto em relação aos aspectos ambientais como nas condições de trabalho e sociais. Esta postura não tem origem no caráter instrumental da demanda do mercado, mas na imposição moral e ética, segundo os princípios substantivos da EdC. Além disso, não se observou qualquer intenção no sentido de esconder os problemas. Ao contrário, nas visitas feitas às empresas, assim como nas respostas aos questionários e entrevistas, tudo foi amplamente exposto.

As evidências observadas já no esboço do projeto lançado por Chiara Lubich em 1991, nos textos dos primeiros autores a escrever sobre o tema, assim como nos resultados das primeiras pesquisas científicas sobre $\mathrm{EdC}^{7}$, foram, em certa medida, confirmadas pelas entrevistas e observações de campo. Como explica um dos empresários, a sua atividade empresarial, após aderir ao projeto EdC, tornou-se um espaço no qual poderia praticar sua crença e as suas virtudes (ascese), tal como na vida pessoal, fazendo com que a empresa passasse por mudanças significativas, adaptando-se à proposta da $\mathrm{EdC}$, que na prática procura incorporar a atividade econômica e em termos organizacionais à espiritualidade da unidade proposta pelo Movimento dos Focolares:

Ao aderir à EdC, entendi que só a adesão não bastava. Precisava mudar a minha empresa concretamente, adequando-a ao novo agir que a EdC propõe e que para nós cristãos trata-se de viver no trabalho a mesma experiência que já vivia na vida pessoal [...]. A EdC propõe que o centro da atividade econômica seja o ser humano, e isso muda tudo. Faz rever certos conceitos, como o de que o concorrente tem que ser eliminado, que o imposto precisa ser sonegado, que o custo ambiental pode ser protelado [...]. O concorrente é um ser humano e como tal é o centro da EdC, assim como eu enquanto empresário e também os meus empregados. Portanto, precisa ser respeitado no seu direito. O imposto, embora muitas vezes mal utilizado pelos governantes, é a nossa contribuição para a sociedade, feita de seres humanos que também precisam ser respeitados nos seus direitos. $\mathrm{O}$ custo ambiental é na prática a demonstração de respeito pela natureza criada por Deus para nós... Além disso, se preservamos a natureza estamos colocando no centro da atividade econômica não só o meio ambiente em si, como erroneamente se possa pensar, mas indiretamente todos os seres humanos que têm o direito a um meio ambiente equilibrado [...]. Colocar o ser humano no centro da atividade econômica, portanto, significa respeitá-lo nas várias ocasiões, seja através do meio ambiente, do seu trabalho, como empregado, cliente ou concorrente, assim como através da coletividade representada pelo Estado.

\section{Princípios de gestão da EdC: contribuições e limites de uma racionalidade de comunhão para fins de gestão ambiental}

As diretrizes para ação das empresas de EdC são traduzidas em sete princípios. Estes princípios são frequentemente citados pelos empresários e podem ser resumidos nos seguintes itens: 1) ter as pessoas como centro da atividade econômica da empresa (público interno); 2) relações comerciais justas e éticas com fornecedores e clientes e governo (público externo); 3) as empresas vendem e negociam produtos e serviços, mas os seus valores éticos e morais são inegociáveis (públicos interno e externo); 4) a empresa deve ser uma comunidade em que todos os interessados tenham voz, prezando pela harmonia física no ambiente de trabalho e das inter-relações (público interno); 5) reservar grande atenção ao ambiente de trabalho e à conservação da

\footnotetext{
${ }^{7}$ Veja Fernandes (2007, p. 111-131).
} 
natureza (público interno e externo); 6) formar e instruir a comunidade trabalhadora (público interno); 7) manter canais de comunicação aberta e sincera entre funcionários e diretores (internamente) e com clientes e fornecedores (externamente).

Além destes princípios, os empresários da EdC devem se guiar pelas sete dimensões do movimento, ilustradas no círculo $^{8}$ da Figura 1. Esta figura emblemática representa resumidamente a concepção do projeto $\mathrm{EdC}$ enquanto modelo de gestão: vermelho representa a dimensão econômica e de partilha, indicadores financeiros, de produtividade e de partilha do lucro como resultado da comunhão; verde, a dimensão da saúde e bem-estar dos membros da empresa e dos destinatários dos bens produzidos, satisfação dos clientes, respeito e conservação da natureza; alaranjado, a dimensão política, de irradiação no sentido de convencimento do valor da proposta nos seus vários aspectos, principalmente substantivos; amarelo, a dimensão transcendental e fidelidade ao projeto no seu sentido fundamental e espiritual; azul, a dimensão estética, harmonia no ambiente de trabalho, tanto em sentido físico como de relações humanas e prática da ética da cooperação; anil, a dimensão da sabedoria, formação desenvolvimento, eficiência, inovação e pesquisa, além do balanço da missão, no sentido de comportamento de sabedoria, mais do que de acúmulo de conhecimento; e violeta, a dimensão da comunicação e de intercâmbio de experiências e interesses entre todas as empresas coligadas, no sentido de através da comunhão efetiva, manter a unidade do projeto em torno dos seus princípios, fundamentos e objetivos.

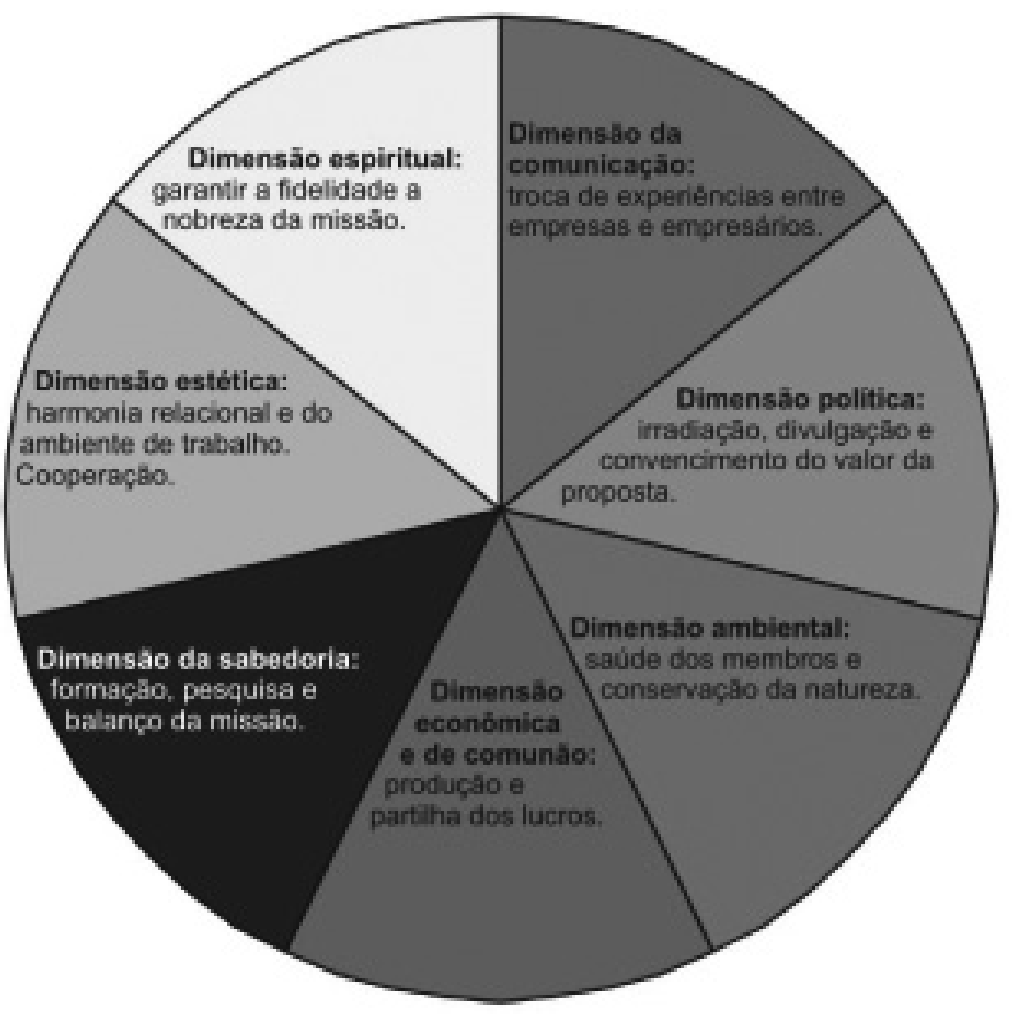

FIGURA 1 - MODELO DE GESTÃO DA EdC BASEADO NOS SETE ASPECTOS

DA ESPIRITUALIDADE DA UNIDADE. FONTE: ADAPTADO DO MODELO APRESENTADO POR RODOLFO LEIBHOLZ, NO CONGRESSO DE EdC EM 2002 (LEIBHOLZ, 2002).

\footnotetext{
${ }^{8}$ Adaptado da apresentação feita por Rodolfo Leibholz - Presidente do Conselho de Administração da ESPRI S/A. e um dos proprietários da FEMAQ - em um Congresso de EdC, em 2002.
} 
O que é expresso por meio deste círculo, entretanto, não deve ser interpretado como uma simples técnica de gestão empresarial. Trata-se, ao invés, de uma ética específica, que tem como finalidade não só certa austeridade administrativa, mas a expansão de uma ética, a ética da unidade ou ética de comunhão, vivida pelo Movimento dos Focolares, para a economia formal. Esta é a essência da questão. Ou seja, tal como Weber (1996) identificou na ética protestante - sem fazer qualquer tipo de comparação entre conteúdos éticos ou entre asceses - é possível identificar que a EdC não se trata de mero bom senso administrativo e comercial, mas sim de uma racionalidade específica cujos critérios são tanto de caráter substantivo como instrumental.

Embora inseridas num contexto de economia de mercado, em que predomina o caráter utilitarista, as empresas de EdC apresentam, também, características substantivas talvez em maior proporção que outras empresas. A explicação para este fenômeno certamente vai além da ética de Benjamin Franklin, descrita por Weber (1996), para quem a honestidade, a pontualidade, a frugalidade e a laboriosidade eram virtudes, porque asseguravam o crédito e garantiam a austeridade. $\mathrm{Na} \mathrm{EdC}$, a centralidade do homem, a valorização das relações interpessoais dos empregados, dos clientes e fornecedores, o respeito às leis e às obrigações com o Estado, o cuidado com o ambiente interno e com a conservação da natureza, a partilha de parte dos lucros, constituem critérios que não podem ser reduzidos a procedimentos utilitaristas ou a finalidades apenas econômicas. Por se tratarem de empreendimentos econômicos, evidentemente são perpassados pela racionalidade instrumental, mas não podem ser reduzidos nem ao economicismo nem ao seu espírito utilitarista. A EdC é uma extensão do Movimento dos Focolares e, portanto, expressa a sua ética e a sua concepção de mundo. A ética do Movimento dos Focolares é uma ética cristã, a ética da unidade, baseada na comunhão material e espiritual, segundo enfatizam seus membros. A EdC enquanto projeto que congrega empresas administradas individual ou coletivamente, é encabeçada por pessoas que são membros do Movimento dos Focolares e, portanto, adeptos da espiritualidade da unidade proposta por Chiara Lubich em 1991.

O círculo da Figura 1 é a síntese desta espiritualidade, na forma de princípios de gestão. O projeto EdC propõe um modelo de gestão que não é unicamente fundamentado na produção de dinheiro, visando exclusivamente ao crescimento econômico, mas propõe uma cultura de comunhão que não nega a produtividade, o crescimento econômico e a produção de dinheiro, mas que os submete a uma racionalidade recheada de valores e princípios éticos, que transcendem ao puro utilitarismo econômico, ora assumindo o utilitarismo religioso, ora se libertando deste e assumindo a gratuidade e a reciprocidade preconizada por Bruni $(2002 ; 2005)$. Esta racionalidade, sintetizada no termo comunhão, é a questão fundamental e, portanto, explicativa do maior ou menor grau de preocupação com as questões sociais e ambientais nas empresas de EdC. Na medida em que for aplicada como uma racionalidade que não se encerra em si, ela é explicativa também de uma série de outras atitudes sociais que são distintas, mas que constitui um todo resultante dos mesmos princípios éticos. Tal como alertou Horkheimer (2002) em relação à atitude de dominação implementada pelo homem moderno, como sendo uma atitude que tem a mesma matriz tanto no que se refere à natureza como em relação aos outros homens, na EdC pode-se afirmar, em termos dedutivos, que a atitude de partilha e responsabilidade social não pode ser descolada da responsabilidade ambiental. São aspectos intrínsecos, constituintes do projeto, que não podem ser vistos como externalidades, mas, justamente ao contrário, são parte do seu dever ser.

É importante ressaltar também que no esquema da Figura 1 estão colocadas tanto a responsabilidade social como ambiental entre os aspectos fundamentais do projeto. Além disso, Chiara Lubich, em texto de 2000, também os inclui nos objetivos e nos princípios da EdC. Em termos empíricos, essas dimensões se materializam em maior ou menor grau nas empresas. Se, por um lado, significam o exemplo de avanço em relação às empresas convencionais, pela sua inerência, por outro lado ainda são princípios não totalmente aplicados pelas empresas e empresários de EdC, principalmente no tocante à dimensão ambiental e, por isso, ainda requerem grande esforço em torná-los empiricamente aplicados. Produzir levando em conta a conservação da natureza e voltado para a justiça social são princípios fundamentais e objetivos da EdC e, por isso, não dependem exclusivamente de pressões externas, porque estão contidos no seu próprio projeto enquanto concepção. Ao contrário, depende da decisão e da fidelidade por parte dos empresários em aplicar esses princípios. Essa decisão, com efeito, é o que pode resultar na materialização da ética da unidade e da racionalidade de comunhão e, consequentemente, na contemplação da dimensão socioambiental como uma atitude que vem de dentro, consequência da ética da qual a própria EdC é resultado, mesmo se a aplicação dessa racio- 
nalidade ainda não seja plena, em função das dificuldades descritas pelos próprios empresários. Depende também, e talvez este seja o maior desafio da EdC, da sua liberação do utilitarismo religioso, sem, no entanto, libertar-se dos princípios fundamentais que a motivam, a gratuidade e a reciprocidade, nos termos de Bruni (2005).

Não obstante o arcabouço valorativo e teórico e as conclusões de boa parte das primeiras pesquisas científicas ${ }^{9}$, a materialização empírica ainda é parcial e requer dos empresários um grande esforço para sua efetividade. Havendo esse esforço, a EdC, que em certa medida já representa um bom exemplo de atuação social e econômica no qual se resgata o equilíbrio entre os critérios substantivos e instrumentais, pode representar também um exemplo em termos socioambientais. Isso porque a racionalidade da $\mathrm{EdC}$ ou a racionalidade de comunhão, como propôs Bruni (2002; 2005), é uma racionalidade que prioriza não só os critérios práticos e de eficiência da racionalidade instrumental/formal/funcional, mas tem como característica importante a submissão desta racionalidade instrumental à racionalidade substantiva, na medida em que os valores determinam o rumo das ações, o que é imperativo para que a responsabilidade socioambiental torne-se prioritária nos processos de gestão. Em outras palavras, a EdC, na proporção em que sua prática for coerente com seus próprios princípios, pode ser a materialização de teorias tais como as formuladas por Polanyi (1994) e Ramos (1989), nas quais se sugere resgatar respectivamente o caráter substantivo da economia e da ação social, o que constitui, por definição, a porta de entrada para a inerência da dimensão socioambiental nas organizações e na própria economia.

Ou seja, baseando-se nestes indicadores e observações, é possível afirmar que há nestas organizações um forte caráter substantivo. Embora sejam empresas atuando na economia de mercado e com forte caráter instrumental, as empresas de EdC apresentam um caráter da racionalidade de valor, no sentido weberiano, devido à presença forte de valores de origem espiritual e religiosa. Tais valores reforçam as dimensões ética, política, estética e moral das atividades desenvolvidas. Essas dimensões, definidas por Weber (1996; 1999), Polanyi (1994) e Ramos (1989) como critérios de valor ou substantivos, estão presentes em todos os níveis do processo de tomada de decisão destas organizações. Observa-se que esta presença faz com que toda a natureza instrumental de uma organização essencialmente capitalista sofra constante pressão, gerando uma tensão entre os valores substantivos já internalizados ou anunciados e a atividade econômica instrumental. Essa tensão tende a fazer com que a organização não só atue como uma unidade de reprodução do capital, mas também como uma organização social, com fins que extrapolam o interesse puramente econômico, como preconizou Ramos (1989).

As empresas de EdC são entendidas pelos empresários e pelos membros do Movimento dos Focolares como um instrumento de comunhão e de amor ao próximo. Esse talvez seja o indicador mais forte de que são organizações que privilegiam uma racionalidade de valor, que pode ser substantiva se transcender o utilitarismo religioso, tanto enquanto concepção de empresa como enquanto prática econômica, em que os meios continuam submetidos aos fins e a racionalidade instrumental submetida ao julgamento dos critérios da racionalidade substantiva. Esse é um indicador também, a partir do qual a economia torna-se meio de buscar a justiça social e a distribuição de renda, na qual a dimensão ambiental entra como um aspecto intrínseco. Isso tende a ocorrer se esse princípio for efetivamente materializado, levando a conservação ambiental e a responsabilidade social a independerem de motivações externas. Nesse sentido, as conclusões que podem ser tiradas desta análise são de que a responsabilidade socioambiental é um valor intrínseco nas empresas de EdC. A sua presença enquanto dimensão dos processos de tomada de decisão e de produção não ocorre porque é reconhecida como uma dimensão motivada unicamente por condicionantes externos, de caráter instrumental, mercadológico ou de marketing. Essa prática, quando ocorre, surge a partir de valores internos, porque é uma condição da espiritualidade da unidade, é um valor que descende de outros valores associados ao amor ao próximo, é um preceito espiritual, ético e moral, relacionado a um conjunto de valores cristãos.

No confronto com a proposição de Ramos (1989), cuja base é a definição aristotélica de "homem político", a constatação é de que a racionalidade presente na EdC pode ser considerada essencialmente substantiva no seu sentido metodológico, na medida em que a ação prática e, portanto, a instrumentalidade destas ações e seus meios, são submetidos ao julgamento de um arcabouço valorativo. A observação a ser feita, porém, é em sentido ontológico, na

\footnotetext{
${ }^{9}$ Cerca de 40 estudos, em nível de mestrado e doutorado, que fornecem indicadores de que as empresas de EdC se preocupam com a conservação da natureza e com os problemas sociais, apontando para uma coerência entre a proposta teórica e a sua aplicação prática (FERNANDES, 2007, p. 111-131).
} 
medida em que são valores específicos, a partir dos quais a ação política livre e consciente é submetida. Essa especificidade, que é dada pela natureza religiosa e espiritual dos valores, tira da racionalidade da EdC o caráter universal da racionalidade proposta por Aristóteles, confinando-a aos limites da crença que representa. A ênfase dada ao cuidado no trato com os clientes, fornecedores, concorrentes, Estado e meio ambiente é na verdade a ênfase cristã do "amor ao próximo", que resulta numa racionalidade específica subordinada a esses valores que são a referência na condução das organizações econômicas da EdC.

\section{Considerações finais}

O objetivo central deste estudo foi compreender a racionalidade das empresas de EdC e suas contribuições para a inserção da dimensão socioambiental nos processos de gestão. A racionalidade de comunhão, inerente à cultura da partilha, constitui a base da ação empresarial de EdC e a aplicação prática de critérios baseados em valores cristãos. Isto é, os fundamentos de tomada de decisão não estão baseados apenas nos objetivos materiais da empresa, segundo os critérios da razão instrumental com finalidades econômicas. Estão baseados também nas relações que se tornam essenciais tanto no âmbito externo à organização (relações com clientes, fornecedores, credores, administração pública, meio ambiente) como no seu âmbito interno. Os princípios de gestão da EdC são valores muitas vezes intangíveis e de caráter não privado sem, no entanto, por isso serem menos reais que os aspectos materiais.

Nesse sentido, as contribuições deste estudo consistem em demonstrar a viabilidade de uma atividade econômica que prioriza os aspectos substantivos, mesmo que a EdC ainda tenha um longo caminho a percorrer nesse sentido. A viabilidade econômica e a responsabilidade socioambiental são resultados diretos do equilíbrio das racionalidades prática (instrumental) e valorativa (substantiva). O que se propõe é a possibilidade de conjugar, em termos de modelo (metodológico), a racionalidade instrumental e a racionalidade substantiva para fins de conservação da natureza. A contribuição, portanto, está nas lições que emanam desta experiência, independente da sua identidade, vícios e limites, como aqueles que emergem da jaula religiosa (WEBER, 1996).

Não se trata, assim, de um modelo de gestão a ser replicado pura e simplesmente, mesmo porque ele ainda não existe de forma sistematizada. Tampouco que todos os empresários devam partilhar da mesma crença proclamada pelos empresários de EdC para que a dimensão socioambiental figure como uma dimensão intrínseca na gestão organizacional. Não é a pretensão aqui fazer apologia à EdC, mas sinalizar que conteúdos éticos, estéticos e morais - e principalmente gratuidade e reciprocidade, próprios da racionalidade substantiva - são essenciais a qualquer modelo de gestão que tenha como finalidade o equilíbrio socioambiental, sobretudo pelo caráter coletivo tanto dos serviços ambientais como dos problemas gerados pela sua degradação.

Ao contrário do que frequentemente se observa nos processos de gestão ambiental normatizados, um processo baseado também na racionalidade substantiva, com equilíbrio entre as dimensões instrumentais e valorativas, resgata a gratuidade que deve estar implícita nas ações de conservação ambiental. O exemplo da EdC e de outras iniciativas solidárias, cujo objetivo esteja fundamentado no interesse coletivo, pode inspirar modelos de gestão ambiental que procurem superar as mazelas de processos fundamentados prioritariamente em ganhos econômicos a partir de estratégias de marketing.

O significado da EdC é ainda essencialmente qualitativo e por isso não deve ser interpretado em termos macroeconômicos, como paradigma de superação do capitalismo, como querem acreditar muitos autores que assim advogam. Os próprios números desmentiriam isto. Ao contrário, como afirmam Pinto e Leitão (2006), deve ser interpretada em termos microeconômicos como forma de gerir marcada fortemente por conteúdos substantivos, mas que ainda está no começo e não pode ser afirmada como um "projeto econômico" ou como um paradigma de gestão. Só será um paradigma de gestão quando for efetivamente sistematizado, a partir de resultados replicáveis e indiscutíveis.

No que se refere à dimensão socioambiental, mesmo se na prática é ainda uma dimensão não totalmente internalizada nas empresas de EdC como um valor, a fidelidade aos seus princípios por parte dos empresários tende a fazer com que essa internalização ocorra mais cedo ou mais tarde, porque ela está plenamente inserida no projeto proposto por Chiara Lubich, assim como nos princípios de gestão apresentados por Rodolfo Leibholz (2002). Portanto, a aposta a ser feita é sempre em relação à fidelidade por parte dos empresários.

A proposta de EdC, se secularizada e efetivamente colocada em prática nas empresas, pode significar também 
um exemplo no qual os conceitos de responsabilidade social e ambiental sejam "reescritos" como dimensões inerentes aos processos de gestão e não apenas como externalidades à organização. A proposição da $\mathrm{EdC}$, em termos ideais, significa uma inversão dessa lógica, na medida em que

\section{Referências}

BRUNI, L. Rumo a uma racionalidade econômica capaz de comunhão. In: (Org.). Economia de Comunhão: uma cultura econômica e suas várias dimensões. Centro de Estudos Pesquisa e Documentação da Economia de Comunhão. São Paulo: Cidade Nova, 2002.

. Comunhão e as novas palavras em economia. São Paulo: Cidade Nova, 2005.

DYE, T. R. Models of politics; some help in thinking about public policy. In: Understanding Public Policy. 5.ed. New Jersey: Prentice Hall, 1994.

FERNANDES, V. A dimensão ambiental em organizações produtivas: uma análise da racionalidade da economia de comunhão (EdC). Florianópolis, 2007. 183 f. Tese (Doutorado) - Universidade Federal de Santa Catarina, Centro Tecnológico. Programa de Pós-Graduação em Engenharia Ambiental. Florianópolis, 2007

GONÇALVES, H. H. A. B. Q. A experiencia dos pioneiros da Economia de Comunhão na liberdade no primeiro decênio (1991-2001) no Brasil: absurdo e graça da mudança de mentalidade do empresário. Tese (Doutorado) - Programas de Pós-Graduação de Engenharia de Produção da Universidade Federal do Rio de Janeiro. Rio de Janeiro, 2005.

HOLLIS, M. Trust witthin reason. Cambridge, 1998.

HUME, D. Investigação acerca do entendimento humano. São Paulo: Nova Cultural, Coleção Os Pensadores, 2000.

HORKHEIMER, M. Eclipse da razão. São Paulo: Centauro, 2002.

LEIBHOLZ, R. Projeto ESPRI 2010. In: Movimento dos Focolares. Economia de Comunhão - Congresso Nacional 2002. São Paulo, 2002. a dimensão socioambiental é transformada em intrínseca e o ser humano é colocado como o centro das atividades da organização "empresa". Ou seja, as finalidades econômicas não são negadas, mas subordinadas às finalidades socioambientais.

LUBICH, C. Risposte alle domande dei focolarini del II anno di formazione. Vídeo de 25/06/1991, acervo Movimentos dos Focolares.

. Á Secretaria Central do Movimento Humanidade Nova. Roma, 1992.

. O Movimento dos Focolares em seus aspectos político e social. Abba-Revista de Cultura. São Paulo: Cidade Nova, v. III, n. 1, p. 9-16, 2000.

MEDEIROS, M. das G. G. de A. Capital social e valores humanos, o desafio relacional contemporâneo nas organizações de trabalho: estudo de caso em duas empresas de Economia de Comunhão. Dissertação (Mestrado) - Programa de Pós-Graduação em Engenharia de Produção, Universidade Federal do Rio de Janeiro. Rio de Janeiro, 2006.

PINTO, M. C. S.; LEITÃO, S. P. Economia de Comunhão Empresas para um Capitalismo Transformado. 1. ed. Rio de Janeiro: Fundação Getúlio Vargas, v. 1. 180 p., 2006.

POLANYI, K. El sustento del hombre. Barcelona: Mondadori, 1994.

RAMOS, A. G. A nova ciência das organizações: uma reconceituação da riqueza das nações. Rio de Janeiro: Fundação Getúlio Vargas, 1989.

SUGDEN, R. Thinking as a team. Social Philosophy and Policy Foundation, n. 10, p. 69-89, 1993.

SCHUMACHER, E. F. O negócio é ser pequeno (smal is beautiful): um estudo de economia que leva em conta as pessoas. 4. ed. Rio de Janeiro: Zahar Editores, 1983.

WEBER, M. A Ética Protestante e o Espírito do Capitalismo. São Paulo: Pioneira, 1996.

Economia e sociedade: fundamentos da sociologia compreensiva. v. 1. Brasília: UnB, 1999.

Recebido em maio de 2010. Aceito em julho de 2010. Publicado em dezembro de 2010. 